\title{
"Individual" Scaling and Overall Evaluation of System Uncertainty
}

\author{
Evgeny A. Kuzmin ${ }^{1}$ \\ ${ }^{1}$ Chair "Corporate Economics", Ural State University of Economics, Ekaterinburg, Russia \\ Correspondence: Evgeny Kuzmin, Chair "Corporate Economics", Ural State University of Economics, \\ Ekaterinburg, 620144, Russia. Tel: 7-906-800-0070. E-mail: KuzminEA@gmail.com
}

Received: October 19, 2014

Accepted: October 29, $2014 \quad$ Online Published: December 10, 2014

doi:10.5539/mas.v9n3p34

URL: http://dx.doi.org/10.5539/mas.v9n3p34

\begin{abstract}
Research in the uncertainty as a phenomenon of the business interaction produces extraordinary challenges in management theory and methodology. The scientific community has usually understood a substantive impact on the uncertainty as a potential opportunity to neutralize a measure of fundamental unpredictability. At the same time, sustainability in any development is a result of balancing between faces of the certainty and the uncertainty. Solving this question, we point out to a need in the selective control. With this end in view, the paper has provided rationalization for a scientific approach to scale (grade) values of the "individual" uncertainty that serves as a quality classification tool for alternatives that are a part of a single case (event) set. Besides, the paper has elaborated a method to evaluate the system uncertainty specifying the standard errors.
\end{abstract}

Keywords: information entropy, uncertainty scaling (grading), uncertainty standard errors, system uncertainty

\section{Introduction}

The uncertainty as a self-condition of an open stochastic system is a principle to develop ideas of risks and their impact on business actors. Making any management decision undoubtedly involves an impact of the uncertainty. This circumstance consistently makes this category a central concept in management theory in different areas of expertise. Systematics for the uncertainty methodology rests on well-grounded ideas of a considered evaluation of its observability. Herewith, its economic or other social implementation sets a goal to define measures able to neutralize or change obvious fluctuations of the uncertainty. Whereby it refers to a need in its subject management, even preventive by its nature.

Management approaches and concepts regarding the uncertainty are available in many papers, such as, for example, Thompson (1967), Sutton, Hickling and Friend (1986), Patricios (1986), Motro and Smets (1997), Viegas (1986), Grote (2004), Grote (2009), Algin (2007), Borisov (2008), Chashin (2011) etc. All of the mentioned authors give the grounds for a number of organizational tools, application of which has no criteria indication. In other words, a management toolkit is not so much focused on a segregated impact, as an overall decrease in the uncertainty. Nevertheless, it is not the only available option. It seems that commitment to structural tranquillity (as a condition of welfare - Kuklin et al. (2014)) can be supplemented with a tolerance towards the uncertainty and the unpredictability, as they are those circumstances (following the academic tradition in the classical school of thought), under which the economic profit appears. In this case, the uncertainty is a kind of a flywheel for development and all sorts of changes, or rather to say, both an in-parallel source to enhance interaction between agents, and a factor that suppresses such interaction. It is balancing between forces of an unrestrained development (the absolute uncertainty) and a fatal decay (the absolute certainty), in which a main task for preventive management lies. Its solution is not only focused on a search for the uncertainty observed characteristics, but also their classification.

Obviously, heterogeneity in the uncertainty significantly complicates a process of academic institutionalisation of approaches. On the one hand, the uncertainty may manifest itself to different extents. The enclosed management toolkits not only may, but also must depend on this. However, selectivity for measures is only achieved by dividing areas of the uncertainty into a number of quality groups, subject to shared principles to make their classification. In other words, types of the qualitatively perceived uncertainty.

The mentioned difficulty occurs due to various reasons, among which there is a nonlinear nature of the function. Since the settlement function for the uncertainty, and the certainty coupled with it, is a not linear one, then a definition for a proportional criterion scale cannot look like a scientifically based solution to the issue. On the 
other hand, the uncertainty is notable for its multi-level nature, hence, has to summarize consistently every aspect of the uncertainty, unpredictability and obscureness. It is generally agreed that the system uncertainty presents an impact of the uncertainty in its specific types. Looking in more detail, it appears that the system uncertainty is nothing but a cumulative set of values of the "individual" uncertainty, in other words, the uncertainty of each alternative within the set. In this regard, this paper attempts to avoid available restrictions and for an academic discussion presents some ways of "individual" scaling (grading) for the uncertainty values, specifying a common view of the system assessment.

\section{Literature Review}

\subsection{Perception of the Uncertainty}

The uncertainty theory is difficult to be referred to as a poorly explored research area. In one aspect or another, the uncertainty covers all spheres of the social life, entirely pointing out to relevance and significance of objectives set hereunder. Many academic papers deal with a nature of the uncertainty, issues of its typification and managerial decision-making. Fundamental ideas for the uncertainty methodology were laid by Cliffe T.E. Leslie (1888), Haynes (1895), Ross (1896), Lavington (1912), Lavington (1913), Knight (1921), Pigou (1912), Borch (1968), Shannon (1948), Brillouin (1960), McCall (1982), Traub, Wasilkowski and Wozniakowski (1988) etc. Fundamental conclusions stated by them have become the basis for a further development of today's scientific thoughts.

There is a prevailing idea that with sufficient simplification the uncertainty can be described as "the missing certainty". Chapman and Ward (2007) follow this stand in their papers. According to them, a corporate project, taken as a basis to be explored, groups the uncertainty according to directions of hazard and threat occurrence. Thus, an obscure and the unpredictable situation comes from both internal and external sources, "that belong to a corporate management team" according to Ward and Chapman (2011). Similar sources are obviously very diverse and essentially present a factor approach. At the same time, Cleden (2009) understands the uncertainty as a "non-material measure of what we have not known". Hence, the uncertainty is not only a lack of information in an academic assumption, saying that a subject is aware of a mechanism of a certain process or a phenomenon, but also a "sufficiency in understanding" with a meaning that the information has been properly interpreted. These signs of an unknown outcome say of available extraordinary errors of the uncertainty that affect its internal content. Other aspects of an information perception of the uncertainty imply a difficulty in communication or implementation of the corporate project, to which Weick (1995) and Winch (2010) have also pointed out. With reference to the given ideas, Ward and Chapman (2003) introduce a general concept of the "ambiguity", which in their view is associated with a "lack of clarity in actors' behaviour..., a missing specification, and a missing structure to consider and solve disputes...". Such an interpretation in this context confirms a perception of the uncertainty as a systemic characteristic feature. However, the mentioned factor approach has considerably complicated a scientific search for a cumulative evaluation for the system uncertainty impact. This is due to both internal and external factors that have not been strictly typed; hence, their analysis is based on an individual evaluation.

An academic perception of the uncertainty has not been limited to an identification of endogenous and exogenous factors. Kreider and Soren (2012) attribute the system uncertainty as the political ambiguity of made decisions, and a lack of decisions in cases when "promises have been made". Herein, the uncertainty appears as a kind of expectation, in the absence of an outcome of which the uncertainty of a future development appears. Herewith, the uncertainty relates more to a state of the environment and can be summarized with a single situation of the unpredictability. Thus, an internal environment of a subject becomes known and certain to an extent permitted by the external environment. In other words, as far as with the uncertainty tension from the outside increases, the inner uncertainty increases too as if being imaged on a progress of processes. Their inconsistency leads to failures in processes, causing a collapse of an entire organizational structure. To support this conclusion, Ball (2007) points out to a variation of the system (like in a natural variability in processes, accidental interruption, etc.), which evidences the uncertainty in an evolutionary aspect. However, the system uncertainty includes, in addition to natural factors of a stochastic development, factors of a subjective perception, as well as direct estimates regarding a standard classification of the uncertainty, i.e. the uncertainty estimates for the environment, decision-making and their consequences.

It is worth noting that resulting errors in terms of the uncertainty are figuratively gathered in a wording "the uncertainty in the uncertainty". In academic papers, the closest analogue, corresponding to a semantic content of the statement, is the system uncertainty, though not in full. It is explored in the context of natural-physical systems (for example, by Sinervo (2003), Norton (2004), Morgan (1994), etc.) to indicate a measurement error 
with the statistical uncertainty (as a requirement of accuracy in measurements of physical quantities). There is no doubt that a parameter estimation is subject to errors and it would be "insufficient when measuring", according to Dieck (2007), not to consider this fact. Traditionally, they include subjectivism of a subject's perception, errors in methodology and technology. Each of them represents an error of a random and system nature. Their fundamental basis is the inaccuracy of any kind, which makes it possible to make a certain confidence interval in estimate measurements according to Morgan and Henrion (1992). The accuracy in this case acts as a probability of the completeness and the accuracy of original estimates, whereas the confidence interval increases the reliability of measurements.

It is also important to raise an issue of uncertainty ranking. Errors in perception, mentioned above, also affect grading of quantitative values of the uncertainty. Most often, a correlation between quality groups and their quantitative values is made through a kind of subjective distribution. However, in a few papers on this subject, scaling is not applied to the uncertainty as such, but to the probability. Such an unjustified substitution of notions one can find in the Guidelines on Communicating Forecast Uncertainty by the World Meteorological Organization (2008), where the occurrence probability for a phenomenon or an event is divided into seven quality groups. A similar approach one can find in earlier academic papers, where they raised this issue for the first time. Thus, Cooke (1906) assumes that the "trust" to estimates (calculations) can be strengthened or weakened with an extra indicator of confidence (coverage probability, phenomenon scale). In a synectic way, such considerations are available in Patt and Schrag (2003) in terms of making subjective comparisons between perception effects for phenomena various in their force and the identical probability of their implementation. However, the completed review of literature has shown that all attempts to solve the issue had failed. Their unproductiveness was a result of the substitution of notions, when instead of the uncertainty they had examined the probability (frequency) of events or phenomena. At the same time, a non-linear nature of the uncertainty does not allow to extrapolate the mentioned approaches in a search for a grounded solution for the task of values' grading. These and other reasons have led to a need in clarifications for not only an evaluation of the system uncertainty, but also for a development of a new idea of the uncertainty scaling process.

\subsection{Evaluation of the Uncertainty}

As the uncertainty is an information measure, it is objectively linked to the concept of entropy, viewed as an assessment of a completeness degree and a quality of information. Shannon (1948) and Brillouin (1960), sometimes being in opposition to each other to solve a number of issues, undoubtedly made a significant contribution to institutionalise a calculation for the information entropy (uncertainty). Nevertheless, they exactly serve as a basis to elaborate an understanding of a quantitative evaluation for the uncertainty and unpredictability. Herein, it is important to explore Shannon's (1963) view of calculating the uncertainty as a measure of a choice for the uncertainty or a scale degree for such a choice. Numerous possible events with the determined probability are discussed as parameters for the calculation. The uniqueness of the probability (case frequency) used in the uncertainty evaluation is also evident in Winkler (1996), O'Hagan and Oakley (2004), who emphasize that the probability is the only way to represent the uncertainty, regardless of difficulties in practice. Shannon's calculation enables evaluating the b-ary entropy that is the entropy that presents the b-y scope of information. Shannon also says that the evaluation is only made for systems with discrete distribution of probabilities (frequencies).

$$
\begin{gathered}
H=-\sum_{i=1}^{n} p_{i} \times \log _{b} p_{i}, \\
H_{i}=-p_{i} \times \log _{b} p_{i}
\end{gathered}
$$

where $H$ is entropy (uncertainty) of $\mathrm{j}$-condition; $H_{i}$ is entropy (uncertainty) of the $\mathrm{i}$-th option (alternative) in j-condition of the set; $p_{i}$ is the probability (frequency); $n$ is a number of options within the set of alternatives.

Somewhat looking ahead, along with a research in the scaling issue, it is worth to be mentioned that grading quantitative values is not only applicable to the uncertainty, but also to the certainty. A scientific rationale for this lies in the binarism phenomenon, implying the inverse proportionality in numerical changes to the entropy and negentropy. The concept of "negentropy" appeared in the statistically interpreted entropy (uncertainty) itself in Boltzmann (1974), who used the "negative entropy" term. A shortened name of "negentropy" refers to Schrödinger's (1944) research of physical phenomena. In his paper, he says, "the life feeds on the negative entropy". Understanding the entropy and negentropy as symmetrical characteristics for an information flow, we conclude that the negative entropy is to be presented using the entropy assessment and striking a constant balance of their sum. 


$$
H E=\log _{b} n+\sum_{i=1}^{n} p_{i} \times \log _{b} p_{i},
$$

where $H E$ is the negentropy of the $\mathrm{j}$-th condition (a group of the set of alternatives).

$$
H E_{i}=\frac{\log _{b} n}{n}-H_{i}=\frac{\log _{b} n}{n}+p_{i} \times \log _{b} p_{i},
$$

where $H E_{i}$ is the negentropy of the $\mathrm{i}$-th alternative in the $\mathrm{j}$-th condition (set of events).

Presented expressions (2) and (3) allow making diagrams for a distribution of these values (Figure 1). Based on fundamentals in analytic geometry one can give basic characteristics and properties of the function distribution. What stands out here is displacement (some concision) of diagrams with the increasing entropy function and the decreasing negentropy function up to a certain limit, acting as a maximum (minimum) of the functions. The author's approach to scaling (grading) of its values is specifically built on the basis of a graphic representation of the "individual" alternative entropy within the set of available ones. Herewith, we need to mention that the approach presented further for an academic discussion is a preliminary and serves as the first solution subject to possible changes in the future.

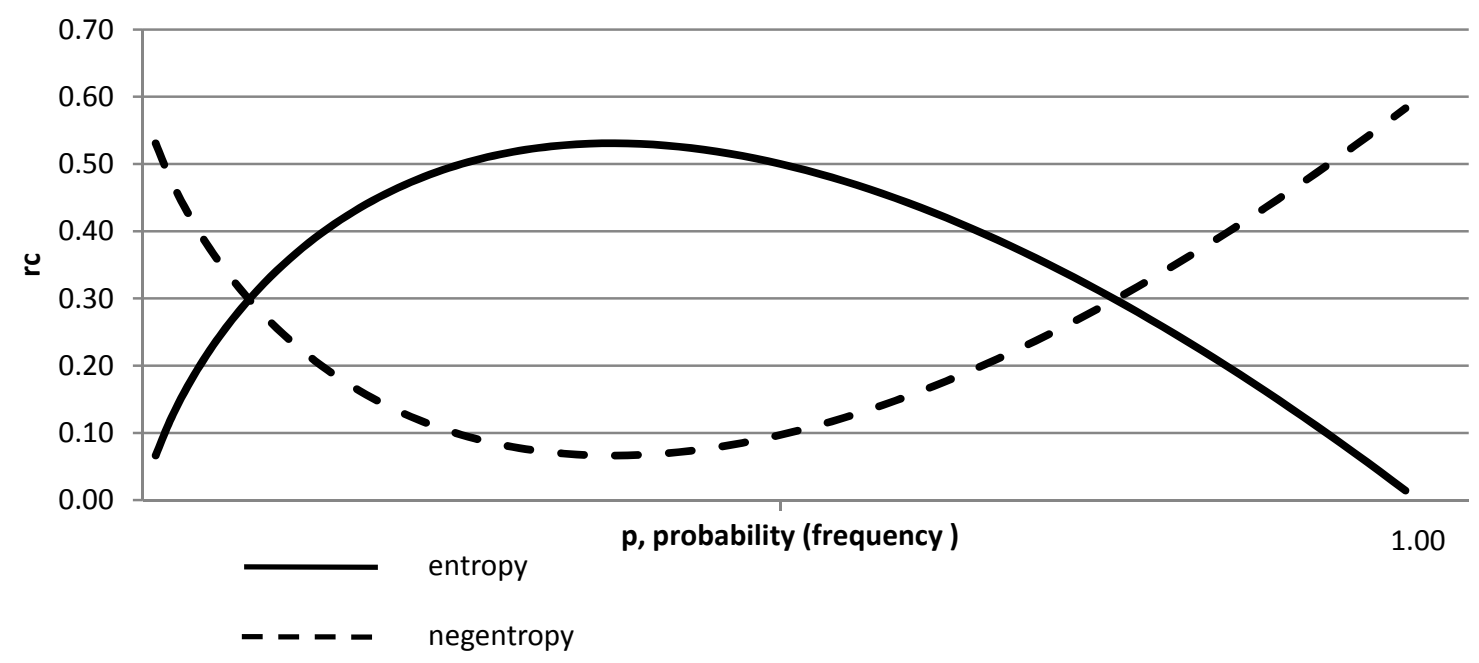

Figure 1. Distribution function diagram for entropy and negentropy of the i-th alternative within the set of allowable options

As for concepts of the uncertainty known in academic sources, it becomes obvious that quality grading (classification) for the entropy follows a way of a subjective definition. The review of literature has failed to show available reasonable criteria or ranges for a change to the uncertainty that (criteria) relate to one or another quality group. A common interpretation only allows talking of three levels, the most often are used in an analytical research. They include high, medium and low level not specifying borders for a numerical change. There are other classifications built on the principle of subjectivism. In this way, in Smirnov (2002), the uncertainty may lay in a range from the low to the ultra-high levels. To our mind, the most complete classification is a typology submitted by Borch (1968). He distinguishes seven types of the uncertainty as follows: zero, quasi-determined, stochastic, with determined distribution of events, with undetermined distribution of damages and a sufficiently large sample, highly stochastic with a small sample and a non-stochastic one. Turning back to the question of scaling (grading), we can state that they are seven degrees of the uncertainty we have used in the approach set by us as an example, but not limited to another differentiation.

We have already said above that the uncertainty was heterogeneous. Structural types were usually described as those that included the uncertainty of environment (of the first kind), decision making (of the second kind) and their consequences (of the third kind) (e.g., in Avdiysky and Bezdenezhnykh (2011)). However, we consider this classification incomplete and demanding clarification. A motivation to complement the types is non-close cyclicality of the uncertainty "generation" process (Figure 2), previously considered only in the linear form. As a result, the process has demonstrated the new uncertainty (of the fourth order), designated by Kuzmin (2012) as 
vartational (Note 1). With its appearance, the idea of systemacity has been changed to some extent. It has become a demarcation barrier in a division of cycles of the sequential changed uncertainties (ibid.). Accumulating emerging institutional conflicts, the vartational uncertainty essentially regulates a possibility of self-organization in time of a saltation.

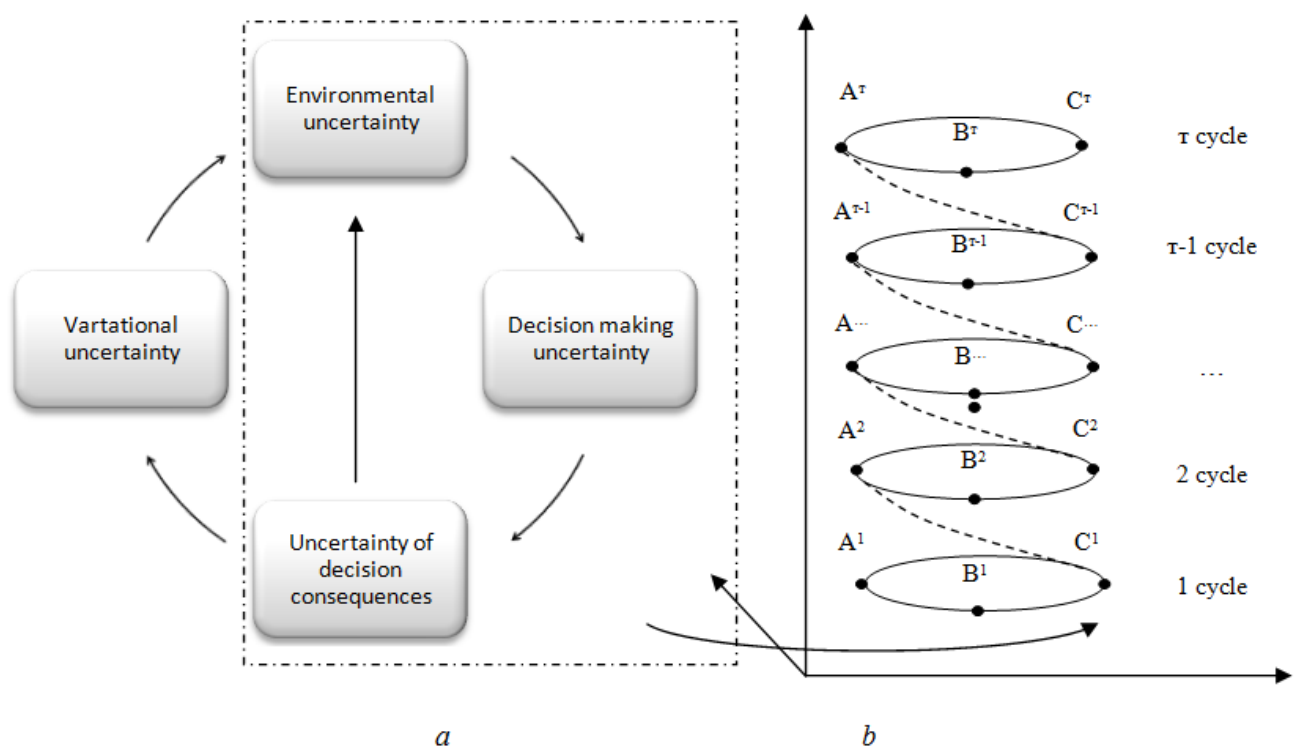

Figure 2. Uncertainty cycle model

(where $a$ - for one cycle; $b$ - in dynamics (for many cycles); environment uncertainty (of the $1^{\text {st }}$ kind); B - decision making uncertainty (of the $2^{\text {nd }}$ kind); C - uncertainty of decision consequences (of the $3 \mathrm{~d}$ kind); _ - - vartational uncertainty (of the $4^{\text {th }}$ kind)).

Obviously, each type of the uncertainty in an analysis of the $\mathrm{j}$-th state has its own quantitative evaluation. However, with no scientific approaches in place to bring together a dependant effect of the entropy of different types, the system uncertainty has remained undetermined. A preliminary solution to this issue had been submitted before by Kuzmin (2012), but had not had at that time those constraints that have become known later. It is this fact that predetermined a need in making the methodology clearer. An important prerequisite was a distinction of components of the uncertainty by type. The system uncertainty can consider necessary components of the evaluation both broadly, and narrowly. If the first lies in a complex, though instantaneous measurement of a motion randomness degree and an enterprise in all its possible aspects, then the latter implies an exclusion from the vartational uncertainty calculation. It seems that a share of the vartational uncertainty accrues to that measure of randomnicity, uncertainty and unpredictability, which is only in the picture in peak periods of the disturbed organizational order. Surely, the vartational uncertainty does not lose its relevance even with the narrowly understood approach. Nevertheless, it is this approach, which assumes ceteris paribus with particularity of events that are not applied to the totality of the system, i.e. those events and phenomena that affect a very small circle of stakeholders, and, the most important, are unable with their consequences significantly change a balance in rules of the game.

A completed review of academic literature suggests that an evaluation of the system uncertainty is an objective set for the first time. Its preliminary solution had included a number of assumptions, a removal of which had allowed making a hypothesis of an available number of standard errors of the uncertainty. All previously known approaches like Shannon (1948) and Brillouin (1960) were approaches of the most general case, and therefore they do not contain hints of the uncertainty evaluation adjustment. Updates made by the author have eliminated this disadvantage.

\section{Methods}

\subsection{System Uncertainty}

The research has elaborated and refined ideas of the system uncertainty, offered in the earlier publication, where the first solution to the issue of the quantitative evaluation was approximate in full; hence, it did not take into account for example specific errors that would be subsequently referred to as standard errors of the uncertainty. 
Another important aspect is a combination of dependent or independent components. We are talking about a paired bond that includes the uncertainty of decision-making and of their consequences. In them, there is a dual conditionality. An exclusion or updates to an alternative or a hypothesis inevitably lead to transformations to a response.

As a result, the high uncertainty of decision-making may also well assume the high uncertainty of their consequences until the decision is made. Later, the solution is almost instantaneously adjusted, avoiding difficulties from an unconscious selection. These and other aspects have inspired a need in clarifying the approach to a calculation of the system uncertainty. As amended, a formalization of the calculation (ceteris paribus) takes the following form:

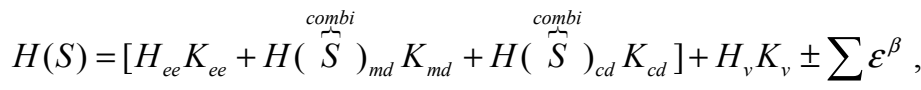

$$
\begin{aligned}
& \left\{\begin{array}{l}
\stackrel{\text { combi }}{S}) \\
H
\end{array}=\sum_{m=1}^{m} H_{j}\left(D_{1} \mid D_{m-1}\right)+\sum_{m=1}^{m} H_{j}\left(D_{m}\right),\right. \\
& \left\{f=p \log _{b}(p) \rightarrow \varepsilon^{\beta} \approx p \frac{\sigma_{p}}{p \ln (b)},\right.
\end{aligned}
$$

where $H(S)$ - system uncertainty; $H_{e e}$ - environment uncertainty; $k_{e e}$ - contribution factor of the environment uncertainty; $H\left(\stackrel{\overbrace{S}^{S}}{c^{c o m b}}\right)_{m d}-$ combined uncertainty of decision-making; $k_{m d}$ - contribution factor of the uncertainty in choice of making managerial decisions; $H(\stackrel{\text { combi }}{S})_{c d}$ - combined uncertainty of decisions consequences; $k_{c d}$-contribution factor of the uncertainty in decisions consequences; $H_{v}$ - vartational uncertainty; $k_{v}$ - contribution factor of the vartational uncertainty; $\varepsilon^{\beta}$ - beta- calculation error, attributable to probability values (similar to the solution in Harris (2003).

It should be said that the uncertainty calculation (4) only takes into account one of possible standard errors. Getting out of the research subject to some extent, it would be useful to clarify an essence of each of them. Such errors can be reasonably divided into three classes: alpha-, beta- and gamma-.

Firstly, the alpha-error of the uncertainty relates to errors of a highly subjectively made set of alternatives. Surely, scenarios for an expected development of the economic system or an agent are of various importance; hence, a number of them may be eliminated from an ongoing uncertainty calculation. However, within the stochastic system with a specific turn of events alternatives may unlikely occur, hence, their exclusion at an evaluation stage would be an error.

Secondly, there is the beta-error of the uncertainty. Its essence lies in making a confidence interval, but for estimates of the probability or frequency of appearing alternatives. Including this error into the uncertainty calculation has a number of difficulties in the methodology. Among them, there is also the uncertainty that lies in the confidence interval of a probability dispersion. After all, an evaluation of the distinct uncertainty as it were, is a calculation made for a single event that is such an event, where a sum of probabilities for alternatives is equal to one. The presence of the confidence interval distorts an overall picture towards either a "lack", or an "excess" in probabilities of extreme cases (within the interval range).

Third, there is the gamma-error of the uncertainty, which says of subjective reasons for a rising uncertainty effort. To our mind, factors of interpretation and commitment (tolerance), able to change a balance of priorities in management and decision-making, play the most active role herein.

Thus, starting from essential features of standard errors of the uncertainty, the calculation of the entropy system value may only but for certain include alpha- and beta- errors with some exceptions. The alpha-error is only permitted in cases where there is some idealized composition of alternatives. A set of hypotheses in their full scope may serve as such a set. However, here a quantitative calculation of the system uncertainty assumes a fixed set of permitted alternatives, which discredits the applicability of the alpha-error. Similar arguments relate to the gamma-error when the obtained values have different interpretations. The only remaining opportunity to obtain the confidence interval in calculations is a usage of the beta-error with respect to probabilities. By the way, it is worth saying here that an idea of the alpha-error inclusion is not lacking in its efficient use. Having added fictitious hypotheses to a composition of alternatives with the low or a negligible probability of their occurrence, it becomes possible to estimate two states, i.e. a conditionally perfect, when a set of hypotheses is the most 
complete, and a conditionally specific, when alternatives meet requirements of the logical compatibility. A resulting difference in uncertainties of these states allows observing an approximate value for the alpha-error (Note 2).

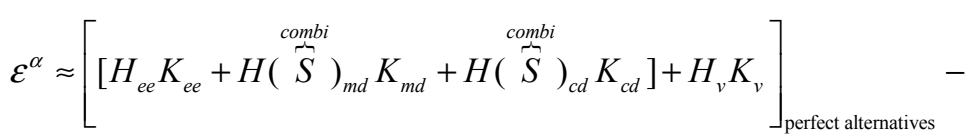

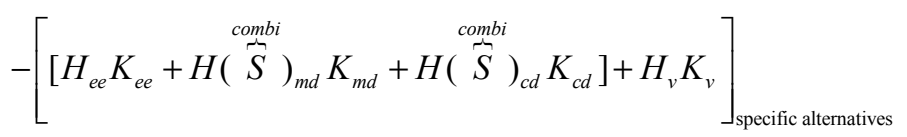

Then the system uncertainty takes a form of (6), which seems to be in full taking into account errors in a computation.

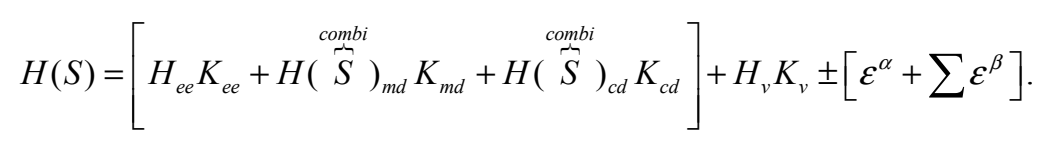

Not included into a calculation of the system uncertainty, the gamma-error in this regard looks like somewhat put aside, but its effects spreads to comparative cognition of dynamics. In other words, the uncertainty looks like a standard of compared situations from the past, a perceptual experience of which cannot be identical. Thus, in a description of the presented approach to an evaluation of the system uncertainty, there have yet remained issues that require a more detailed research, but now we can say that the approach is getting closer to its methodology perfection.

\subsection{Scaling (Grading) the "Individual" Uncertainty}

The abovementioned clarification for the system uncertainty evaluation allows going to grounding the scaling of the "individual" uncertainty (it should be said that this refers to the uncertainty of the i-th alternative of the set of permitted for the $\mathrm{j}$-th event). This is essentially the first step to make a balanced policy for preventive control, where the uncertainty is no longer considered a unique phenomenon of the uncertainty and ambiguity, but a tool for a controlled development.

An uncertainty scaling (grading) technique includes two aspects. Firstly, the uncertainty of the specific alternative of the total set of such aspects is explored. With special measures taken, it allows harmonizing the implementation of the generic case entropy. Secondly, the uncertainty of an entire event is explored. An overall evaluation may point out to a need in preventive management, or rather a choice of appropriate interventions. It is worth saying that scaling can be also applied to the negentropy (certainty).

The approach by default involves distinguishing some qualitative classification groups for the uncertainty. As a mere example, seven levels are taken as a basis (similar to the uncertainty typification by Borch (1968)). A number of such groups may vary either upward, or downward, depending on action-oriented purposes of the research. All levels are designated with serial numbers, assuming that the first number describes the lowest possible quantity uncertainty of the "individual" alternative, while the last - its maximum value. A graphical distribution of the uncertainty (according to Figure 1) points out to a displaced symmetry. As a result, two intervals for each the uncertainty area appear, i.e. those of an increase and decrease. Herein, intervals for levels of uncertainties and intervals of probabilities for each of those parts are made independently.

A scaling scheme de jure lies in a search for values of the probability, with which there is an equality achieved in an area of figures for each level (Figure 3). For an initial and final levels of the uncertainty, where the probability may not be equal to 1 or 0 , an assumption is applied of crossing the function diagram in an area, as close to 1 and 0 as possible, but not equal to them. I.e., the probability of a starting point of the first level approaches zero, while the probability of the endpoint of the last level approaches one. Otherwise, a solution to the scaling issue losses its significance. 


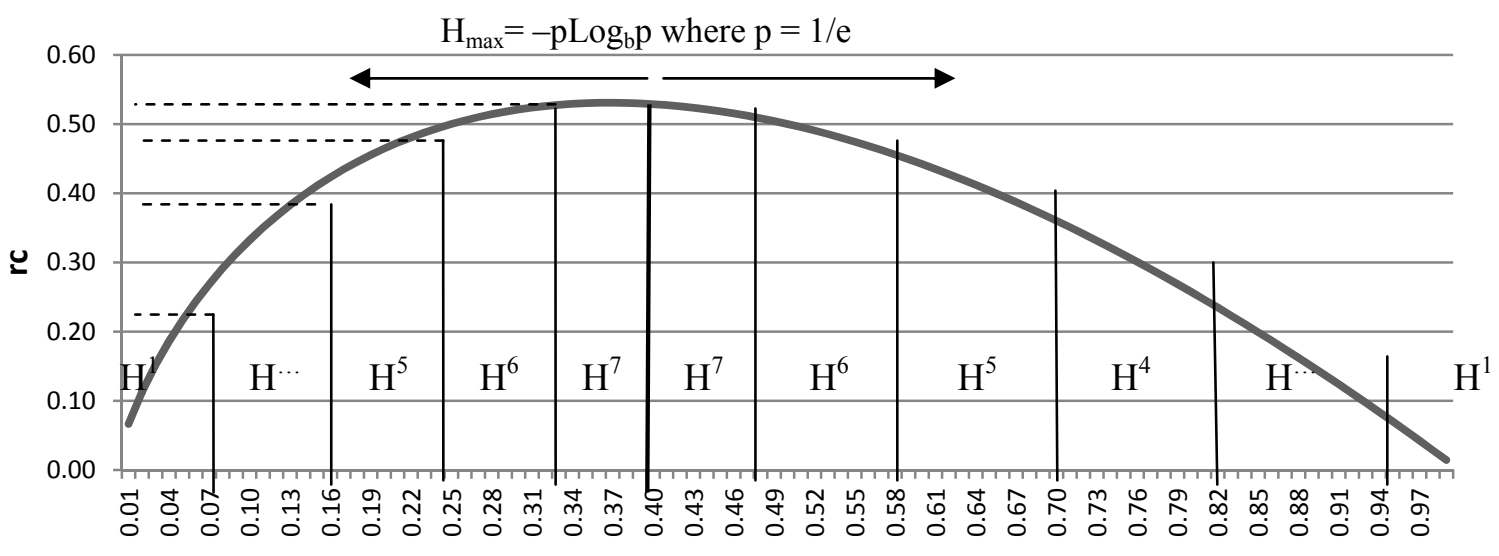

$\mathrm{S}(\mathrm{H})^{\mathrm{r}}$

$\mathrm{S}(\mathrm{H})^{\mathrm{u}}$

p, probability (frequency) for case occurence

Figure 3. Graphic representation for the approach to scaling (grading) the "individual" uncertainty

In a generic case, one needs to define and represent with symbols limits for changes to probabilities per each level of the uncertainty. As it is seen from the diagram, sides of the increasing and decreasing uncertainty are binary intervals. They are they that make a final scale of values for both the "individual" uncertainty, and the probability of a corresponding i-th alternative. Symbols, we have introduced, are given in Table 1.

Table 1. Notating probability intervals for levels of the uncertainty

\begin{tabular}{lllllllll}
\hline \multicolumn{7}{c}{ For the side of the increasing uncertainty } \\
\hline Level notation & $\mathrm{H}^{1 \mathrm{r}}$ & $\mathrm{H}^{2 \mathrm{r}}$ & $\mathrm{H}^{3 \mathrm{r}}$ & $\mathrm{H}^{4 \mathrm{r}}$ & $\mathrm{H}^{5 \mathrm{r}}$ & $\mathrm{H}^{6 \mathrm{r}}$ & $\mathrm{H}^{7 \mathrm{r}}$ \\
Upper limit & $p^{l r}$ & $p^{2 r}$ & $p^{3 r}$ & $p^{4 r}$ & $p^{5 r}$ & $p^{6 r}$ & $p^{7 r}$ \\
Low limit & $p^{0 r}$ & $p^{I r}$ & $p^{2 r}$ & $p^{3 r}$ & $p^{4 r}$ & $p^{5 r}$ & $p^{6 r}$ \\
\multicolumn{1}{c}{ For the side of the decreasing uncertainty } \\
Level notation & $\mathrm{H}^{7 \mathrm{u}}$ & $\mathrm{H}^{6 \mathrm{u}}$ & $\mathrm{H}^{5 \mathrm{u}}$ & $\mathrm{H}^{4 \mathrm{u}}$ & $\mathrm{H}^{3 \mathrm{u}}$ & $\mathrm{H}^{2 \mathrm{u}}$ & $\mathrm{H}^{1 \mathrm{u}}$ \\
Upper limit & $p^{6 u}$ & $p^{5 u}$ & $p^{4 u}$ & $p^{3 u}$ & $p^{2 u}$ & $p^{1 u}$ & $p^{0 u}$ \\
Low limit & $p^{7 r}$ & $p^{6 u}$ & $p^{5 u}$ & $p^{4 u}$ & $p^{3 u}$ & $p^{2 u}$ & $p^{1 u}$ \\
\hline
\end{tabular}

Having paid attention to symbols, let us proceed with a calculation as such. As it appears from Figure 3, for corresponding levels of the uncertainty an area of figures is marked and included in the zone of increasing and decreasing functions. In this case, the total area is calculated by summing each of them. Differences areas of increase and decrease, as well as bias graphic functions allow you making a logical conclusion that the area of these zones are not equal. Consequently, the evaluation of their area should be carried out independently.

Let us consider the increase area, as a sample computation performed to scale the "individual" uncertainty. Firstly, the $p^{7 r}$ probability is maximum by the uncertainty value for complete functions, that is $p^{7 r}=1 / \mathrm{e}$ (where $e$ is the base of natural logarithm). Secondly, a lower limit of the uncertainty increase area by the probability $\mathrm{p}^{\mathrm{or}} \rightarrow$ 0 , but at that $\mathrm{p}^{0 \mathrm{r}} \neq 0$. On the other hand, in the uncertainty decrease area the lower limit of probabilities $\mathrm{p}^{0 \mathrm{u}} \rightarrow 1$ and at that $p^{0 u} \neq 1$. Thus, we are able to calculate separately a size for the uncertainty increase and decrease areas:

$$
\mathrm{S}\left(\mathrm{H}_{\mathrm{i}}\right)^{\mathrm{r}}=\int_{p^{0 r}}^{p^{7 r}}-p_{i} \times \log _{b} p_{i}=c^{r} \text { and } \mathrm{S}\left(\mathrm{H}_{\mathrm{i}}\right)^{\mathrm{u}}=\int_{p^{7 r}}^{p^{0 u}}-p_{i} \times \log _{b} p_{i}=c^{u},
$$

where $\mathrm{S}\left(\mathrm{H}_{\mathrm{i}}\right)^{\mathrm{r}}$ is a size of the increase area for the information entropy function, $\mathrm{rc}^{2} ; \mathrm{S}\left(\mathrm{H}_{\mathrm{i}}\right)^{\mathrm{u}}$ is a size of the decrease area for the information entropy function, $\mathrm{rc}^{2}$.

According to the logic approach, figures made with the uncertainty levels within the ascending or descending areas should be equal in size. Hence, if we denote with $t$ a number of these degrees of the uncertainty (qualitative 
classification groups), an area of each of them will be equal to the determined quantity $-\mathrm{c}^{\mathrm{r}} / \mathrm{t}$ or $\mathrm{c}^{\mathrm{u}} / \mathrm{t}$. Based on these quantities, one can proceed with sequential finding the probability interval for each level. As a methodological example, we have shown a way to find the boundary probability for the first level of the uncertainty (an increase area). Other boundary probabilities can be calculated by analogy and are not presented hereunder. A search for a quantitative value of the sought probability involves a solution to the following equation:

$$
\begin{gathered}
\int_{p^{o r}}^{p^{1 r}}-p_{i} \times \log _{b} p_{i}=\frac{c^{r}}{t}, \\
p_{i}\left(p^{0 r}\right) \times \log _{b} p_{i}\left(p^{o r}\right)-p_{i}\left(p^{1 r}\right) \times \log _{b} p_{i}\left(p^{1 r}\right)=\frac{c^{r}}{t}, \\
p^{0 r} \times \log _{b} p^{o r}-p^{1 r} \times \log _{b} p^{1 r}=\frac{c^{r}}{t}, \\
p^{0 r} \times \log _{b} p^{o r}-p^{1 r} \times \log _{b} p^{1 r}=\frac{c^{r}}{t}, \\
\log _{b} p^{o r p^{0 r}}-\log _{b} p^{1 r p^{1 r}}=\frac{c^{r}}{t}, \\
\log _{b} \frac{p^{o r p^{0 r}}}{p^{1 r p^{1 r}}}=\frac{c^{r}}{t}, \\
\text { given that, } \underset{p^{o r} \rightarrow 0}{\lim ^{o r} p^{0 r}}=1 \quad \text { we get } p^{1 r p^{1 r}}=\frac{1}{b^{\frac{c^{r}}{t}}},
\end{gathered}
$$

where $\mathrm{p}^{\mathrm{lr}}$ is a sought quantity of the probability interval limit.

The resulting equation with one undetermined parameter raised to the power of the same figure, may have its solution using the Lambert function (for details see Corless et al. (1996), original manuscript - Lambert (1758):

$$
p^{1 r}=\frac{\ln \frac{1}{b^{\frac{c^{r}}{t}}}}{W\left(\ln \frac{1}{b^{\frac{c^{r}}{t}}}\right)}, \rightarrow p^{1 r}=\frac{\ln b^{-\frac{c^{r}}{t}}}{W\left(\ln b^{-\frac{c^{r}}{t}}\right)}, \rightarrow p^{1 r}=\frac{-\frac{c^{r}}{t} \ln b}{W\left(-\frac{c^{r}}{t} \ln b\right)},
$$

where $\mathrm{W}$ is the Lambert function.

A result of the mathematical solution is the found probability value $\mathrm{p}^{1 \mathrm{r}}$, which later by analogy with the approach will be used in a search for the next undeterminate $-\mathrm{p}^{2 \mathrm{r}}$ and so on until probability intervals are made up. Thus, a calculation is consistently made either from the beginning, or from an end of the uncertainty function of the individual alternative (the $\mathrm{i}$-th alternative within the set of the $\mathrm{j}$-th event). With the $\mathrm{p}^{1 \mathrm{r}}$ found, there is an opportunity to calculate the uncertainty inherent for the first level, which will also be located within the boundaries of the interval, dual at that. In other words, a qualitative classification of the uncertainty is getting quantitative criteria. With eliminated methodological constraints and difficulties in choosing measures of preventive control, there is a partial solution to the scientific task of harmonizing the set of alternatives. As a result, it (the set of alternatives) acquires features of an event under control; hence, risks and threats from the uncertainty are in an acceptable range for the sustainable development.

Thus, the scaling (grading) approach proposed for an academic discussion has allowed with reason to arrive at a ratio between quality groups of the perceived entropy and a quantitative measure of the "individual" uncertainty as such. This task is of high relevance in many administration domains. After all, accurate selectivity in a choice of preventive measures becomes possible specifically as a result from alternatives grouping. Herein, a particular applied meaning of the applied uncertainty scaling method is accentuated.

\section{Conclusion}

To summarize the findings, we can make a number of the following conclusions significant for the research. Obviously, the theory and methodology of the uncertainty are quite extensive. In them ideas and hypotheses from many subject areas have been embodied, pointing out to an inter-disciplinary nature. The uncertainty scaling (grading) method is a clear example in this regard. The all-in-one nature of the approach makes it 
possible to extrapolate the research logic to other parametric values, different because of their non-linear distribution function. However, in terms of scientific tasks set hereunder, scaling has given perhaps the most important evidence-based math rationale for the phenomena qualitatively perceived with quantitative criteria, which had been previously limited to evaluation subjectivism. Graduation accuracy in terms of the uncertainty is difficult to be overestimated as besides a selective impact the preventive management is permitted to harmonize the entire set of alternatives.

Making the system uncertainty evaluation more precise is another important aspect in the research. Standard errors included in the calculation and the uncertainty dependent and independent development taken into account have allowed the approach to achieve its methodological perfection. However, it is still impossible to say of a comprehensive nature of the method to count the system uncertainty. It is quite possible that a range of specific errors would be supplemented. At the same time, the area of academic interests includes an appearance of possible new typed (kinds) of the uncertainty, which figuratively deepen abstract concepts of the fundamental unpredictability of phenomena. However, even now we can for certain say of the efficiency of solutions to the objectives set by the paper.

\section{Acknowledgement}

The Russian Scientific Foundation (RSF) supported this research, project No. 14-18-00574 "The Information and Analytical System Anti-Crisis: Region Diagnosis, Threat Assessment and Scenario Forecasting to Preserve and Strengthen Economic Security and Raise Welfare in Russia".

\section{References}

Algin, V. (2007). Overcoming uncertainty. [Preodolenie neopredelennosti]. Risk Management, 1.

Avdiysky, V. I., \& Bezdenezhnykh, V. M. (2011). Uncertainty, variability and inconsistency for the analysis of risk behaviour economic systems [Neopredelennost', izmenchivost' i protivorechivost' v zadachakh analiza riskov povedeniia ekonomicheskikh sistem]. Effective Crisis Management, 3.

Ball, D. R. (2007). Managing multi-agent risk and system uncertainty using options-based decision policies. ProQuest.

Boltzmann, L. (1974). The second law of thermodynamics. In McGinness, B. (Ed.), Ludwig Boltzmann: Theoretical Physics and Philosophical Problems: Selected Writings. Dordrecht: D. Reidel, 14-32. http://dx.doi.org/10.1007/978-94-010-2091-6_2

Borch, K. H. (1968). The economics of Uncertainty. Princeton University Press.

Borisov, A. (2008). Major approaches to uncertainty management in business structures. [Osnovnye podkhody k upravleniiu neopredelennost'iu v predprinimatel'skikh strukturakh]. Entrepreneurship, 3.

Brillouin, L. (1960). Science and Information Theory [Nauka i teoriia informatsii]: [translated from English]. Moscow: Fizmatgiz.

Chapman, C., \& Ward, S. (2007). Managing project risk and uncertainty: A constructively simple approach to decision making. Chichester, UK: John Wiley \& Sons.

Chashin, V. V. (2011). Staff marketing and uncertainty management in the company internal environment. [Marketing personala i upravlenie neopredelennost'iu vnutrennei sredy]. Russian Businessman, 4.

Cleden, D. (2009). Managing project uncertainty. Farnham, UK: Gower.

Cooke, W. E. (1906). Forecasts and verifications in Western Australia. Monthly Weather Review, 34, 23-24. http://dx.doi.org/10.1175/1520-0493(1906)34\%3C23:FAVIWA\%3E2.0.CO;2

Corless, R. M., Gonnet, G. H., \& Hare, D. E. et al. (1996). On the Lambert W-function. Advances Computational Maths, 5. http://dx.doi.org/10.1007/BF02124750

Dieck, R. H. (2007). Measurement uncertainty: methods and applications. USA: ISA.

Grote, G. (2004). Uncertainty management at the core of system design. Annual Reviews in Control, 28. http://dx.doi.org/10.1016/j.arcontrol.2004.03.001

Grote, G. (2009). Management of Uncertainty: Theory and Application in the Design of Systems and Organizations. Springer. http://dx.doi.org/10.1007/978-1-84882-373-0

Harris, D. C. (2003). Quantitative Chemical Analysis. Sixth edition. New York: W.H. Freeman and Company.

Haynes, J. (1895). Risk as an Economic Factor. The Quarterly Journal of Economics, 9(4). http://dx.doi.org/10.2307/1886012 
Knight, F. H. (1921). Risk, Uncertainty and Profit. Boston: Hart, Schaffner \& Marx. http://dx.doi.org/10.1017/CBO9780511817410.005

Kreider, W., \& Soren, I. V. (2012) Systemic Uncertainty: An Examination of Its Causes and Repercussions. Undergraduate Economic Review, 9(1), Article 5. Retrieved from http://digitalcommons.iwu.edu/ uer/vol9/iss $1 / 5$

Kuklin, A. A., Naydenov, A. S., Nikulina, N. L., \& Tarasyeva, T. V. (2014). Transformation of theoretical-methodological approaches and methodical tools of the individual and territory welfare diagnostics. Part 1. From spreading to the alternative diagnostics approaches (background). Economy of Region, 3, 22-36.

Kuzmin, E. A. (2012). Business systems in conditions of the uncertainty and certainty: Evaluating entropy and negentropy values. [Organizatsionno-ekonomicheskie sistemy $\mathrm{v}$ usloviiakh neopredelennosti i opredelennosti: otsenka znachenii entropii i negentropii]. Upravlienets, 11-12 (39-40), 44-54.

Kuzmin, E. A. (2012). Uncertainty and certainty property estimation of organizational-economic system. European Social Science Journal, 3(19), 480-493.

Lambert, J. H. (1758). Observationes variae in mathesin puram. Acta Helveticae Physico-Mathematico-Anatomico-Botanico-Medica, 3, 128-168.

Lavington, F. (1912). Uncertainty in its relation to the rate of interest. Economic Journal, 22(87), 398-409. http://dx.doi.org/10.2307/2221946

Lavington, F. (1913). The social interest in speculation on the Stock Exchange. Economic Journal, 23(89), 36-52. http://dx.doi.org/10.2307/2222208

Leslie, T. E. Cliffe. (1888). The Known and the Unknown in the economic world. Essays in Political Economy. L.: Longmans.

McCall, J. (1982). The economics of information and uncertainty. NBER Books, 82(1). http://dx.doi.org/10.7208/chicago/9780226555652.001.0001

Morgan, D. A. (1994). Handbook for EMC testing and measurement. IET. http://dx.doi.org/10.1049/PBEL008E

Morgan, M. G., Henrion, M., \& Small, M. (1992). Uncertainty: a guide to dealing with uncertainty in quantitative risk and policy analysis. Cambridge University Press. http://dx.doi.org/10.1017/CBO9780511840609

Motro, A., \& Smets, P. (1997). Uncertainty Management in Information Systems: From Needs to Solutions. Springer. http://dx.doi.org/10.1007/978-1-4615-6245-0

Norton, A. J. (Eds.) (2004). Observing the universe: a guide to observational astronomy and planetary science. Cambridge University Press.

O'Hagan, A., \& Oakley, J.E. (2004). Probability is perfect, but we can't elicit it perfectly. Reliability Engineering and System Safety, 85, 239-248.

Patricios, N. N. (1986). A perceptual-behavioural perspective of decision-making under uncertainty. In Wilkin, L., Sutton, A. (Eds.), The Management of Uncertainty: Approaches, Methods and Applications. Springer (pp. 241-251). http://dx.doi.org/10.1007/978-94-009-4458-9_11

Patt, A., \& Schrag, D. (2003). Using specific language to describe risk and probability. Climatic Change, 61, 17-30. http://dx.doi.org/10.1023/A:1026314523443

Pigou, A. C. (1912). Wealth and Welfare. London: Macmillan. Pt. V.

Ross, E. A. (1896). Uncertainty as a factor in production. Annals, American Academy, VIII, 92-119. http://dx.doi.org/10.1177/000271629600800204

Schrödinger, E. (1944). What is life? Cambridge University Press. http://dx.doi.org/10.1017/CBO9781139644129

Shannon, C. E. (1948). A mathematical theory of communication. The Bell System Technical Journal, $27,3$. http://dx.doi.org/10.1002/j.1538-7305.1948.tb01338.x

Shannon, C. E. (1963). Papers on Information Theory and Cybernetics [Raboty po teorii informatsii i kibernetike]: [translated from English]. Moscow: Publishing House of Foreign Literature.

Sinervo, P. K. (2003). Definition and treatment of systematic uncertainties in high-energy physics and astrophysics, PHYSTAT2003, SLAC, Stanford, California, September 8-11, 122-129.

Smirnov, E. A. (2002). Making Managerial Decisions. [Razrabotka upravlencheskikh reshenii]. Moscow: UNITY-DANA. 
Sutton, A., Hickling, A., \& Friend, J. (1986). The Strategic Choice Approach to Managing Uncertainty. In Wilkin L., Sutton A. (Eds.), The management of uncertainty: Approaches, methods, and applications. Chapt. The strategic choice approach to managing uncertainty, 14-52. http://dx.doi.org/10.1007/978-94-009-4458-9_2

Thompson, J. D. (1967). Organizations in Action; Social Science Bases of Administrative Theory. New York: McGraw-Hill.

Traub, J., Vasilkovsky, G., \& Vozhnyakovsky, K. (1988). Information, Uncertainty, Complexity [Informatsiia, neopredelennost', slozhnost']: [translated from English]. Moscow: Mir.

Viegas, J. M. (1986). Uncertainty, complexity and decision-making processes. In Wilkin, L., Sutton, A. (Eds.). The Management of Uncertainty: Approaches, Methods and Applications. Springer, 252-263. http://dx.doi.org/10.1007/978-94-009-4458-9_12

Ward, S., \& Chapman, C. (2011). How to Manage Project Opportunity and Risk: Why Uncertainty Management Can be a Much Better Approach Than Risk Management. John Wiley \& Sons.

Ward, S., \& Chapman, C. (2003). Transforming project risk management into project uncertainty management. International Journal of Project Management, 21, 97-105. http://dx.doi.org/10.1016/S0263-7863(01)00080-1

Weick, K. E. (1995). Sense making in organizations. Thousand Oaks, CA: Sage.

Winch, G. M. (2010). Managing construction projects: an information processing approach (2nd ed.). Chichester: Wiley-Blackwell.

Winkler, R. L. (1996). Uncertainty in probabilistic risk assessment. Reliability Engineering and System Safety, 54. http://dx.doi.org/10.1016/S0951-8320(96)00070-1

World Meteorological Organization. (2008). Guidelines on Communicating Forecast Uncertainty. PWS-18 WMO/TD, 1422 .

\section{Notes}

Note 1. The vartational uncertainty should be referred to as the uncertainty in changing "rules of the game". Errors from contrasting norms and mechanisms in institutional regulation, missing or misfitting requests for control and responses to them are also included in the semantics of the vartational uncertainty. However, the vartational uncertainty is not a substitute for the environment uncertainty. It changes a state of the environment, making new quasi-conditions, which are a consequence from made and variative-base implemented managerial decisions. The "vartational uncertainty" concept is in its etymology associated with the Latin expression for the variability - vertibilis and variabolis, which has become the basis for a definition of the new type of the uncertainty.

Note 2. A special role of the uncertainty alpha-error (5) lies in its indicative function. While the beta-error has only positive values, and actually sets the confidence interval, the alpha-error may have both a positive and negative value. Symptoms of deviations in a difference of the system uncertainty calculated for the conditionally perfect and conditionally specific situation, give an idea of a quality for the set of alternatives. Location of the alpha-error in the negative area seemingly shows their excessive coverage that goes beyond an ideal distribution, to which only probable hypothesis are subject. With a positive value of an error, in contrast, the set of alternatives is only limited to those ends that are considered acceptable and logical structured. At the same time, a real situation implies that the set of hypotheses included in the evaluation of the uncertainty, will be somewhat incomplete, making possible to find a value for the alpha-error. On the practical side in the question of calculating the system uncertainty, errors in the aggregate should only have a positive value. Otherwise, errors compensate each other's effect, while a value of the system uncertainty would be as much exact as possible, which is not typical for stochastic systems.

\section{Copyrights}

Copyright for this paper is retained by the author(s), with first publication rights granted to the journal. This is an open-access paper distributed under the Terms and Conditions of the Creative Commons Attribution License (http://creativecommons.org/licenses/by/3.0/). 